\title{
A case of severe acute respiratory syndrome coronavirus 2 with acute thrombotic cerebral infarction and generalized thrombosis
}

\author{
Sylvia Nikolaeva Genova ${ }^{1}$, Mina Miroslavova Pencheva ${ }^{2}$, Alexander Georgiev Ivanov ${ }^{3}$ \\ From ${ }^{1}$ Associate Professor, Department of General and Clinical Pathology, Medical University, Faculty of Medicine, University Multiprofile Hospital \\ for Active Medical Treatment "Sveti Georgi”, ${ }^{2}$ Senior Assistant Professor, Department of Medical Physics and Biophysics, Medical University-Plovdiv, \\ ${ }^{3}$ Assistant Professor, Department of General and Clinical Pathology, Medical University, Faculty of Medicine, University Multiprofile Hospital for \\ Active Medical Treatment "Sveti Georgi", Plovdiv, Bulgaria
}

\begin{abstract}
The full spectrum of coronavirus disease 2019 (COVID-19) has not been fully described yet. COVID-19 is associated with a high risk of thrombotic complications such as venous thromboembolism and cerebrovascular disease. Here, we report an autopsy case of a 55-year-old woman diagnosed with severe viral pneumonia complicated by acute cerebral infarction and venous and arterial thrombosis in different organs. The patient died due to severe acute respiratory syndrome coronavirus 2. Macroscopically and histologically, in addition to viral pneumonia and diffuse hemorrhages, fibrin clots were found in arteries and venous vessels of medium and large size in the brain, lungs, and pancreas. Propagation of cerebrovascular thrombosis has led to extensive cerebral infarction. The dating of this infarction, according to the macroscopical findings and the histological changes, was between 24 and $48 \mathrm{~h}$ before death. This case confirms the hypothesis on the risk of generalized arterial and venous thromboses in coronavirus infection.
\end{abstract}

Key words: Autopsy case, Brain infarction, Coronavirus disease 2019 pneumonia, Generalized thrombosis

A $\mathrm{n}$ acute respiratory disease, caused by a novel coronavirus (severe acute respiratory syndrome coronavirus 2 [SARSCoV-2], previously known as 2019-nCoV), the coronavirus disease 2019 (COVID-19) has caused a pandemic spread throughout the world [1]. The full spectrum of COVID-19 has not been fully described yet. COVID-19 is associated with a high risk of thrombotic complications such as venous thromboembolism and cerebrovascular disease. Many patients with severe coronavirus infection have been reported to be in a hypercoagulable state and to develop complications such as venous and arterial thrombosis [2,3]. Some authors describe a different spectrum of neurological manifestations such as brain stroke, neuromuscular disorders, and meningoencephalitis.

Here, we report an autopsy case of a 55-year-old woman diagnosed with severe viral pneumonia complicated by acute cerebral infarction and venous and arterial thrombosis in different organs.

\section{CASE REPORT}

A55-year-old Bulgarian woman complained of weakness, coughing, inability to expectorate, and fever for the past 3 days. The patient

\section{Access this article online}

Received - 29 July 2021

Initial Review - 14 August 2021

Accepted - 10 September 2021

DOI: $10.32677 /$ ijcr.v7i9.3045 had moderate arterial hypertension as an accompanying disease. Antibiotic treatment was prescribed by the general practitioner but the fever persisted and shortness of breath occurred. A week later, her state continued to worsen, with fever (as high as $38^{\circ} \mathrm{C}$ ), dry cough, generalized weakness, and shortness of breath.

The patient was admitted to the Pulmonology department where the patient was diagnosed with pneumonia. The administered treatment included Oseltamivir $-2 \mathrm{mg} \times 75 \mathrm{mg}$, Vaborbactam $3 \mathrm{~g} \times 1 \mathrm{~g}$ i.v., Levofloxacin $500 \mathrm{mg}$ i.v daily. After 4 days of treatment with no effect and exacerbation of the symptoms, she was transferred to the intensive care unit with confluent, bilateral pneumonia. Auscultation revealed exaggerated vesicular breathing with diffuse wheezing at both lung bases.

The X-ray demonstrated non-homogenous striped shadows in the lower and middle lung parts and around the hilus, while the hilar spaces were congested. The arterial blood pressure gradually rose up to 180/100 Hg. A diagnosis of COVID-19 was confirmed by polymerase chain reaction. Rapid antibody test (IgM, IgA) against SARS-CoV-2 was positive. During the hospital stay, clinical laboratory parameters from the routine blood tests were indicated (Table 1). Blood gas analysis showed an extreme decrease in oxygen saturation in tissue and blood plasma with a decompensated respiratory alkalosis (Table 2).

Correspondence to: Mina Miroslavova Pencheva, Department of Medical physics and Biophysics, Faculty of Pharmacy, Medical University Plovdiv, Bulgaria, Plovdiv, 15A Vasil Aprilov Bul., Plovdiv, Bulgaria. E-mail: Mina.Pencheva@mu-plovdiv.bg

(C) 2021 Creative Commons Attribution-NonCommercial 4.0 International License (CC BY-NC-ND 4.0). 
Table 1: Routine blood tests and differential blood count

\begin{tabular}{lcc}
\hline Routine blood tests & Value & Ref \\
\hline Creatin Kinase & $712 \mathrm{U} / 1$ & $22-198 \mathrm{U} / 1$ \\
Lactate dehydrogenase & $1402 \mathrm{U} / 1$ & $140-280 \mathrm{U} / 1$ \\
Activated partial thromboplastin time & $29.6 \mathrm{~s}$ & $30-40 \mathrm{~s}$ \\
Fibrinogen & $4.15 \mathrm{~g} / 1$ & $2-4 \mathrm{~g} / 1$ \\
D-Dimers & $2.960 \mu \mathrm{g} / \mathrm{ml}$ & $0-0.5 \mu \mathrm{g} / \mathrm{ml}$ \\
C-reactive protein & $88 \mathrm{mg} / 1$ & $0-8 \mathrm{mg} / 1$ \\
Lymphocytes & $0.49 \%$ & $25-45 \%$ \\
Eosinophils & $0.0 \times 10^{9} / 1$ & $30-350$ \\
Monocytes & $0.11 \%$ & $2-8 \%$ \\
\hline
\end{tabular}

Table 2: Blood gas analysis test

\begin{tabular}{lcc}
\hline Blood gas analysis test & Value & Ref \\
\hline pCO2 $(\mathrm{T})$ & $29.0 \mathrm{mmHg}$ & $35-45 \mathrm{mmHg}$ \\
$\mathrm{pO} 2(\mathrm{~T})$ & $55.0-59.0, \mathrm{mmHg}$ & $>79$ \\
cBase. B.oc) c-AB & $4.0 \mathrm{mEq} / \mathrm{l}$ & $-2-+2 \mathrm{mEq} / 1$ \\
cBase $(\mathrm{Ecf}) \mathrm{c}-\mathrm{SBE}$ & $2.0 \mathrm{mmol} / \mathrm{l}$ & $-3-+3 \mathrm{mmol} / \mathrm{l}$ \\
$\mathrm{CBASE}$ & $-1 \mathrm{mmol} / 1$ & $-3-+3 \mathrm{mmol} / 1$ \\
$\mathrm{cHCO} 3-(\mathrm{P}, \mathrm{st}) \mathrm{c}-\mathrm{SBC}$ & $27.0 \mathrm{mEq} / 1$ & $22-26 \mathrm{mEq} / 1$ \\
$\mathrm{ctCO} 2(\mathrm{~b}) \mathrm{c}-\mathrm{tCO} 2$ & $26.0 \mathrm{mmol} / \mathrm{l}$ & $23-30 \mathrm{mmol} / 1$ \\
$\mathrm{pH}(\mathrm{T})$ & 7.55 & $7.35-7.45$ \\
\hline
\end{tabular}

The following medical procedures were performed during hospitalization: Orotracheal intubation, assisted ventilation, central venous catheter, urethral catheterization. Despite the treatment used, her condition deteriorated and 10 days since the onset of the disease her state became critical and she died.

A complete autopsy of the patient was performed. The mucosae of the trachea and bronchi were hyperemic, their walls were thickened. In their lumens, there was a bloody, mucus matter. Macroscopically, the lungs were enlarged, each one weighing $750 \mathrm{~g}$, with a purple-red color and soft, easily torn consistency. Some nodular areas showed increased density. The cut surface was dark red, with diffuse hemorrhages. Dark purple thrombi were coming out from the blood vessels. The brain was highly edematous. A massive zone of tissue softening involving almost the entire left hemisphere and indicate massive anemic brain infarction was noticeable. Macroscopically, in one of the basal blood vessels, propagated thrombosis was observed. Propagation of thrombi was observed along the arterial vessels in cerebri posterior and cerebri media. In the same vessels, any atherosclerotic changes were not observed. The cerebral ventricles were not clearly distinguishable because of colliquative necrosis (Fig. 1a). The heart was normally situated in the chest, of normal shape and size. The pericardial sheets and epicardium were smooth, shiny, and translucent. The thickness of the heart chamber, just below the mitral valve was $20 \mathrm{~mm}$ (sign of myocardial hypertrophy). The cut surface clearly showed the thickening of the muscle fibers. The papillary muscles were mobile. On dissection, the coronary arteries and other branches of the upper aorta were unaffected by the pathological changes.

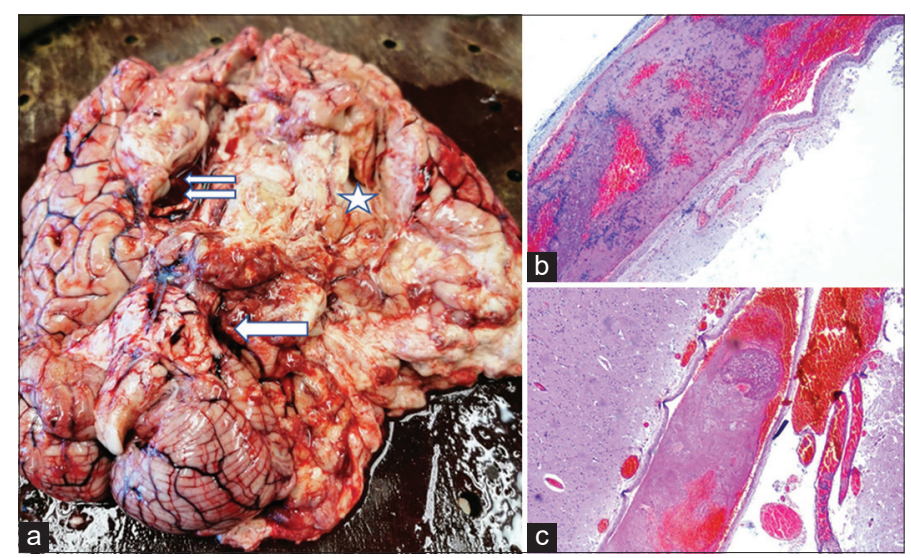

Figure 1: (a) Propagating thrombosis in the blood vessels of the brain, a. cerebri posterior (arrow), a. cerebri media (double arrow). Infarcted area*. Gross picture; (b) Fibrin thrombus in a. cerebri posterior of the brain (H and E, Original magn. $\times 40$ ); (c) Fibrin thrombus in a. cerebri media ( $\mathrm{H}$ and $\mathrm{E}$, Original magn. $\times 40)$

Yellowish areas of gelatinous plaques were found along the intima of the abdominal aorta without the presence of fully developed atherosclerotic plaques. The liver had a normal shape, with slightly increased size. The capsule was smooth, shiny, evenly stretched in all directions, with dense consistency. The cut surface was variegated, brownishyellow, and the lobular structure was not clearly visible. The gallbladder was situated normally, with bile contents, without concretions. The pancreas was of normal location, shape, and size. The cut surface was coarse-grained. The surface of the kidneys was finely granulated with several small serous urinary cysts. The vacant adipose tissue was increased in the hilus. The cortex was slightly atrophic, and the boundary between it and the medulla was not clearly distinguishable. The ureters revealed no visible pathological changes and flowed properly into the bladder. The immediate cause of death was determined to be acute dilatation of the right heart cavities and acute cor pulmonale due to viral pneumonia with SARS-CoV-2-syndrome and acute extensive, thrombotic brain infarction in the left cerebral hemisphere. Other findings related to the cause of death were severe vascular hyperemia and focal hemorrhages in the internal organs, initial chronic venous stasis in the liver and generalized vascular thrombosis in the lungs, pancreas, and brain.

Histologically, the brain tissue was loose, necrotic, with perivasal and pericellular edema. A large propagated thrombus was found in arterial blood vessels, which has caused a vast brain infarction in the left cerebral hemisphere (Fig. 1b and c). In the lungs, multiple desquamated alveolocytes were found, with minimal inflammatory infiltrate. Alveolar walls were with hyperemia and diffuse hemorrhages per diapedesin, hyaline membranes, and multinucleated virus-transformed cells (Fig. 2a). The histological picture in the lungs was of a hemorrhagic desquamative giant-cell viral pneumonia and the formation of syncytial structures from alveolocytes (Fig. 2b). Lots of fibrin thrombi were found, mostly in the mediumsized veins and arteries (Fig. 2c). Fibrin thrombi were also found in the medium-sized veins and arteries of other organs, 


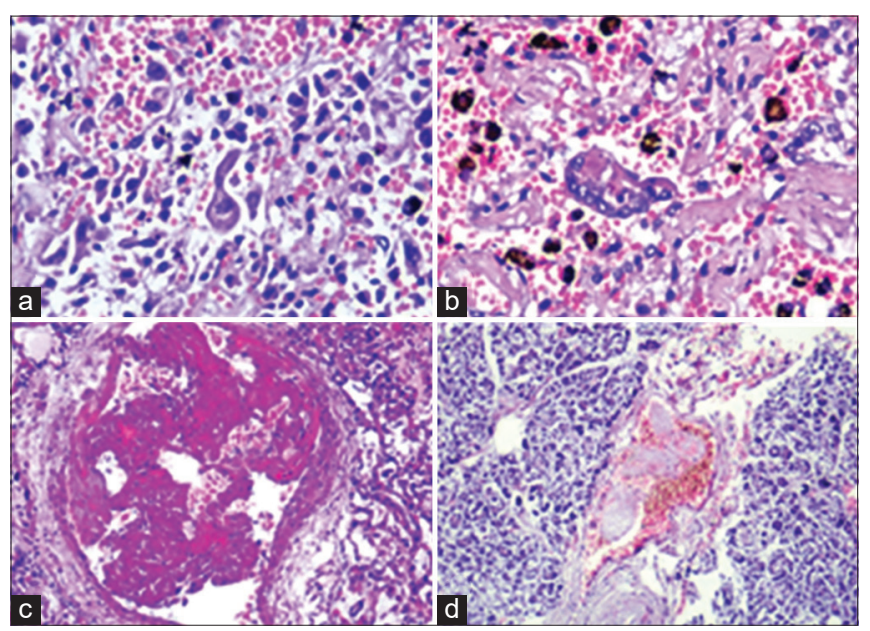

Figure 2: (a) Desquamative virus pneumonia with virus-induced cellular transformation $(H$ and $E$, Original magn. $\times 400)$; (b) Formation of syncytial structures from alveolocytes $(\mathrm{H}$ and $\mathrm{E}$, Original magn. $\times 400$ ); (c) Fibrin thrombus in a medium-sized pulmonary blood vessel (H and E, Original magn. $\times 100)$; (d) Fibrin thrombus in a pancreatic vein $(\mathrm{H}$ and $\mathrm{E}$, Original magn. $\times 200)$

such as the brain and pancreas (Fig. 2d). We did not find inflammatory cells in any of the vessels in the different organs. Active replication and release of the virus in epithelial cells, endothelial cells may cause the host cell to undergo pyroptosis (pro-inflammatory apoptosis) and release damage-associated molecular patterns (DAMPs), activating oxidant stress, generating pro-inflammatory cytokine and chemokine release. This mechanism leads to activation of both the extrinsic and intrinsic coagulation pathways to cause thrombosis. The thrombosis of large-sized cerebral blood vessels that lead to a subtotal anemic infarction of the left brain hemisphere was considered as one of the immediate causes of death. The dating of this infarction, according to the macroscopic findings and the histological changes, was between 24 and $48 \mathrm{~h}$ before death. Because of this, the cerebrovascular accident was considered a complication of the coronavirus infection. Other findings related to the cause of death were generalized vessel thrombosis in the lungs, pancreas, and brain.

\section{DISCUSSION}

SARS-CoV-2 belongs to $\beta$-coronavirus and has been shown to enter cells through binding with ACE-2 receptors, found mainly on the membrane of the alveolar epithelium and endothelium. Activation of endothelial cells is thought to be the primary driver for the increasingly recognized complication of thrombosis [1,2]. The immune dysregulation characteristic of severe COVID-19 infection may be initiated by "pyroptosis," a particularly proinflammatory form of apoptosis [2,3]. In most cases, there is also an elevation in the D-dimers. In the presented case the D-dimers, fibrinogen, activated partial thromboplastin time were increased by multiple times.

In COVID infection, there is a high correlation between pulmonary thrombosis and SARS syndrome in the lungs [4]. Huertas et al. [5] explained that the early pathogenesis in
COVID-19 pneumonia was defined by widespread endothelialitis affecting multiple organ systems. Analysis of precapillary vessels showed that in four of the seven lungs from patients with COVID19 , thrombi were consistently present in pulmonary arteries with a diameter of 1-2 mm, without complete luminal obstruction [6]. At the same time, systemic inflammation is commonly observed, with elevated levels of C-reactive protein, fibrinogen, and cytokines such as interleukin-6 [7]. These include the increased production of tissue factors and amplification of the coagulation cascade, resulting in increased production of thrombin and fibrin. Clot formation is extremely rapid and also resistant to breakdown [8].

The high rate of pulmonary thrombosis in COVID-19 conceivably lies in the coalescence of several mechanisms which disturb Virchow's triad within the lungs: The intense endothelial inflammation, leading to "in situ" thrombosis, including microvascular thrombosis and altered pulmonary blood flow in response to the parenchymal process $[9,10]$. The presumed pathogenic mechanism is also schematically described by Price et al. [10] as when coronavirus infects cells, active replication and release of the virus may cause the host cell to undergo pyroptosis and release DAMPs, activating oxidant stress, and generating pro-inflammatory cytokine and chemokine release from nearby epithelial cells, endothelial cells and alveolar macrophage [10-12].

Besides pulmonary thrombosis, increased brain involvement is also described in the literature, such as brain stroke, neuromuscular disorders, and meningoencephalitis. A large study by Ghannam et al. [11] showed that $87.5 \%$ of the cerebrovascular infarctions were due to ischemic strokes followed by cerebral vein thrombosis $(5 \%)$, intracerebral hemorrhages $(5 \%)$. In the review, ischemic stroke was the most common neurological manifestation, occurring in $42.7 \%$ of the subjects, with large vessel occlusion representing $77 \%$ of the ischemic stroke [11,12].

In the literature, there are a few published cases of cerebral thrombosis, most of them reported by radiologists, using mainly computed tomography imaging [12]. Sugiyama et al. [13] demonstrated cerebral thrombosis in the left transverse sinus. Zhou et al. [14] reported a case of a 75-year-old woman diagnosed with severe COVID-19, complicated by acute cerebral infarction and venous thrombosis of the bilateral lower extremities.

\section{CONCLUSION}

Patients with COVID-19 are in a hypercoagulable state, with blood stasis and endothelial injury due to inflammation. In the present case, the patient had a medical history of hypertension with moderate left ventricular hypertrophy without cardiac decompensation and pulmonary congestion. The patient's vessels had no severe or complicated atherosclerotic changes in the aorta or in the cerebral arteries to initiate thrombogenesis. This case demonstrates that viral endothelial injury and endothelial dysfunction alone are enough to trigger thrombogenesis in both arteries and veins. Our case lists the COVID 19 infection as a generalized disease. 


\section{AUTHOR CONTRIBUTORS}

S.N.G., M.M.P., A.G.I. designing study, acquiring data, analyzing data, writing manuscript. All authors participated in revising and approving the manuscript.

\section{ACKNOWLEDGMENTS}

The authors express their gratitude to Assoc. Prof. Bivolarsky for aiding in the diagnosis of the case and to Dr. Popivanova for providing macroscopic photo.

\section{REFERENCES}

1. Guo YR, Cao QD, Hong ZS, Tan YY, Chen SD, Jin HJ, et al. The origin, transmission and clinical therapies on Coronavirus disease 2019 (COVID-19) outbreak-an update on the status. Mil Med Res 2020;7:11.

2. Varga Z, Flammer AJ, Steiger P, Haberecker M, Andermatt R, Zinkernagel AS, et al. Endothelial cell infection and endotheliitis in COVID-19. Lancet 2020;395:1417-8.

3. Cookson BT, Brennan MA. Pro-inflammatory programmed cell death. Trends Microbiol 2001;9:113-4.

4. Chong PY, Chui P, Ling AE, Franks TJ, Tai DY, Leo YS, et al. Analysis of deaths during the severe acute respiratory syndrome (SARS) epidemic in Singapore: Challenges in determining a SARS diagnosis. Arch Pathol Lab Med 2004;128:195-204.

5. Huertas A, Montani D, Savale L, Pichon J, Tu L, Parent F, et al. Endothelial cell dysfunction: A major player in SARS-CoV-2 infection (COVID-19)? Eur Respir J 2020;56:2001634.

6. Ackermann M, Verleden SE, Kuehnel M, Haverich A, Welte T, Laenger F, et al. Pulmonary vascular endothelialitis, thrombosis, and angiogenesis in
COVID-19. N Engl J Med 2020;383:120-8.

7. Chen G, Wu D, Guo W, Cao Y, Huang D, Wang H, et al. Clinical and immunological features of severe and moderate coronavirus disease 2019. J Clin Invest 2020;130:2620-9.

8. Panigada M, Bottino N, Tagliabue P, Grasselli G, Novembrino C, Chantarangkul V, et al. Hypercoagulability of COVID-19 patients in intensive care unit. A report of thromboelastography findings and other parameters of hemostasis. J Thromb Haemost 2020;18:1738-42.

9. Klok FA, Kruip MJ, van der Meer NJ, Arbous MS, Gommers DA, Kant KM, et al. Incidence of thrombotic complications in critically ill ICU patients with COVID-19. Thromb Res 2020;191:145-7.

10. Price LC, McCabe C, Garfield B, Wort SJ. Thrombosis and COVID-19 pneumonia: Theclot thickens! Eur Respir J 2020;56:2001608.

11. Ghannam M, Alshaer Q, Al-Chalabi M, Zakarna L, Robertson J, Manousakis G. Neurological involvement of Coronavirus disease 2019: A systematic review. J Neurol 2020;267:3135-53.

12. Al-Ani F, Chehade S, Lazo-Langner A. Thrombosis risk associated with COVID-19 infection. A scoping review. Thromb Res 2020;192:152-60.

13. Sugiyama Y, Tsuchiya T, Tanaka R. Cerebral venous thrombosis in COVID19-associated coagulopathy: A case report. J Clin Neurosci 2020;79:30-2.

14. Zhou B, She J, Wang Y, Ma X. A case of Coronavirus disease 2019 with concomitant acute cerebral infarction and deep vein thrombosis. Front Neurol 2020;11:296.

Funding: The article is part of a study of coronavirus disease 2019 on a National Project - coronavirus disease 2019 HUB -Information, Innovations, and Implementation of Integrative Research activities in Bulgaria. Medical University Plovdiv, Bulgaria; Conflicts of Interest: None Stated.

How to cite this article: Genova SN, Pencheva MM, Ivanov AG. A case of severe acute respiratory syndrome coronavirus 2 with acute thrombotic cerebral infarction and generalized thrombosis. Indian $\mathrm{J}$ Case Reports. 2021;7(9):405-408. 